\title{
Improved Selling of Treasury Bills
}

\section{Flavio Menezes}

$\mathrm{T}$ There is a renewed interest in studying the optimal procedure to sell Treasury Bills. This debate, which has its roots in Milton Friedman's proposal to use uniform-price auctions (Friedman, 1960), has concentrated on the advantages of the uniform versus the discriminatory-price auction. In a uniformprice auction, bids (which include both price and quantity) are ordered by price, from the highest to the lowest. The auctioneer accepts quantities up to the amount it is selling, but all winners pay the price equivalent to the highest losing bid. In a discriminatory-price auction, bids are ordered similarly, but each agent pays the price she bid. Alternatively, we can describe this mechanism using yields instead of prices. In this case bids are ordered by yield, from the lowest to the highest and the auctioneer accepts quantities up to the amount it is selling. Each winner pays the (discounted) price she bid.

A recent study by Bartolini and Cottarelli (1994) reports that discriminatoryprice auctions are used in over ninety per cent of the 42 countries surveyed by them. For example, Denmark, Nigeria and Switzerland are among the few countries that use uniform-price auctions to sell their debt. Belgium, Tanzania, France, Gambia, Mexico and Italy had used uniform-price auctions in the past but have switched to discriminatory price auctions recently.

The Reserve Bank of Australia nuns weekly auctions of Treasury Notes with maturities of five, thirteen and twenty six weeks. Bonds are auctioned off every two or three weeks. These notes and bonds are sold through discriminatory-price auctions. In the 1998-99 financial year, the Reserve Bank sold Treasury Notes in excess of $\$ 44$ billion with average yields varying from 4.66 to 4.99 . Thus, a reduction in the average yield of a few basis points might represent a reduction in the cost of financing the government's debt of several million dollars. This is clearly an important issue and, therefore, this paper aims at jump starting the debate on how the Australian government should sell its debt. This debate is stated in its original form below. By using the insights from a new theory of auctions, this article seeks to explain why the original debate is misleading and explore the implications for Treasury bill auction design.

\section{A Brief Account of the Salomon Brothers Scandal}

The source of the renewed interest in auction formats can be traced to the Salomon Brothers scandal of 1991, when this large dealer was accused of manipulating an

Flavio Menezes is a Senior Lecturer in the Department of Economics, Faculty of Economics and Commerce, The Australian National University and Associate Professor at the Graduate School of Economics (EPGE/FGV) in Rio de Janeiro. 
auction for two-year notes. This section, which draws on Bikhchandani and Huang (1993), provides a brief account of the Salomon Brothers scandal, illustrating fears of market manipulation that are shared by most central banks around the world. For example, manipulation issues may raise concerns in Australia given the small number of primary dealers.

Treasury securities are issued and handed to the winners a few days after the auction. These securities are then resold in secondary markets. One such market is the when-issued market that works as follows. After an announcement of the amount of securities to be auctioned, primary dealers begin trading forward contracts on these securities. The seller of a forward contract guarantees to deliver and the buyer guarantees to take delivery of a certain quantity of securities. On delivery, the buyer pays the forward price set at the time the forward contract was sold. The delivery date is the issue date - that is the reason why this market is known as the when-issued market. Trading in the when-issued market continues after the auction and up until the issue date of the security.

A 'short squeeze' occurs when some of those who sold when-issue contracts fail to buy the securities in the auction. They are then forced to pay more to buy the when-issued contracts back. If many bidders hold positions on the whenissued market and one bidder successfully bids for a large amount at an unusually high price in the auction, then this bidder can obtain a high price in the whenissued market. All those who took short positions are forced to buy from the bidder who owns most of the units sold at the auction. Those short sellers have to service a demand for bonds issued at that particular date. This is what Salomon Brothers was accused of doing in an auction for two-year notes in 1991.

This episode has revived a debate that dates to the late 1950 s and early $1960 \mathrm{~s}$ on how to sell Treasury securities. This debate is summarised below. In addition, as a result of the scandal, a Joint Report on the Government Securities Market (Department of the Treasury, Securities and Exchange Commission, and Board of Governors of the Federal Reserve System, 1992) proposed two alternative auction formats for the sale of Treasury securities, namely, an ascending-price uniformprice mechanism and a sealed-bid uniform-price auction along the lines described in the previous section. Most of the debate has ignored the former mechanism and focused instead on the latter mechanism. Both mechanisms are discussed below.

\section{The Debate}

The debate on how to sell Treasury Bills has mostly been based on an imperfect analogy between single-unit and multiple-unit auctions. This erroneous view suggests that the discriminatory-price auction is a multiple-unit version of a firstprice auction, and that the uniform-price auction can be viewed as a multiple-unit version of a second-price auction. In a first-price single-unit auction, the bidder with the highest bid wins and pays the amount of her bid. In a second-price single-unit auction, the bidder with the highest bid wins and pays the amount of the second highest bid. Under some circumstances the second-price auction is equivalent to the familiar English oral auction. 
One can understand why economists and policy makers alike have used this analogy: the theory of single-unit auctions is well developed and its predictions well known to economists. For example it is well known that, because the amount bid affects only the probability of winning and not the amount paid, bidders bid their true private valuations in a second-price single-unit auction. It is this feature which leads to an efficient outcome. The erroneous analogy then suggests that bidders bid their true valuations in a uniform-price multi-unit auction.

Friedman, for example, suggests in an article in the Wall Street Journal (28 August 1991) that 'A [uniform-price] auction proceeds precisely as [a discriminatory-price] auction with one crucial exception: All successful bidders pay the same price, the cut-off price. An apparently minor change yet it has the major consequence that no one is deterred from bidding by fear of being stuck with an excessively high price. You do not have to be a specialist. You need only know the maximum amount you are willing to pay for different quantities.'

Merton Miller (New York Times, 15 September 1991) also suggests that '[In a uniform-price auction] you just bid what you think it's worth.' Along the same lines, the Joint Report on the Government Securities Market (1992) states that 'In the case envisioned by Friedman, the uniform-price awards would make the auction demand curve identical to the secondary market demand curve.'

It is also known, from the theory of auctions of a single object, that when bidders' values are affiliated - roughly speaking, this means that if one bidder thinks that the values of the other bidders are high then her own value is also high - the second-price sealed-bid auction generates more revenue than the first-price sealed-bid auction. If the analogy were correct, then the uniform-price auction would generate more revenue than the discriminatory-price auction.

Finally, Chari and Weber (1992), argue that 'While the theory has not been completely developed for that situation [when bidders have demand schedules], the economic logic of the arguments for the single-object environment seem likely to carry over'.

It is worth noting that the US Treasury experimented with a particular type of uniform-price auction during 1992-1993 with inconclusive results as to revenue generation (see, for example, Malvey, Archibald and Flynn, 1996). Later we will review some of the empirical and experimental literature on this controversy.

The next section summarises some of the findings of the new theory of auctions and explains why the analogy between single-object auctions and multiple-object auctions is incorrect.

\section{The New Theory of Auctions and its Implications}

Why are auctions where multiple objects are sold different from auctions of a single object? When competing for a single object, it suffices for a bidder to outbid the opponent with the highest bid. (Only standard auctions where the winner is the individual with the highest bid are considered here). Now suppose there are $n$ bidders who are competing for $k$ identical objects $(n>k)$ and let me focus on auctions where the winning bids are the $k$ highest ones. For the special 
case where each bidder only wants one object, then it also suffices for an agent to forecast only one bid, namely, the bid of the opponent with the $k^{\text {th }}$ highest bid. If this individual outbids the opponent with the $k^{\text {th }}$ highest bid then she receives one of the $k$ identical objects. In this case, analysed in detail in Menezes (1999), the single unit auction logic does carry over.

Now suppose each bidder wants up to $k$ objects. In this case, each bidder has to forecast the bids of the opponents with the $k$ highest and think about all the possible implications. For example, a bidder may have the two highest bids and, therefore, this bidder wins two objects. Or a bidder may have the $(k-1)^{t h}$ highest bid, winning only one object. This is a very difficult problem that economists have not yet being able to solve in general. Therefore, there is no reason to believe that the results of the theory of auctions of a single object that were used to support the choice of a uniform-price auction to sell Treasury securities will hold with multiple-unit demands.

Although a general theory of auctions of multiple objects does not exist, economists know enough today to realise that the results from single-object auction theory will not hold in general when multiple objects are sold. In what follows some of the results from the new theory of auctions of multiple units are outlined.

Menezes and Monteiro (1995) consider a private-independent-value model where $Y$ divisible objects are sold, agents have demand curves for the objects and are allowed to bid any amount in the interval $[0, Y]$. One can think of the demand curves as the demand curves of individual traders in the secondary market. Menezes and Monteiro assume full information. However, their work may be extended as to the case where each bidder knows her own demand but only the distribution of her opponents' demand functions. Bidders submit pairs $(p, q)$, where $p$ denotes a price-bid and $q$ a quantity-bid.

In this framework, a bidder's expected profits, conditional on winning a certain quantity $q$ at a certain price $p$, is simply the difference between the consumer's surplus up to $q$ and the payment $p q$. For the simple case where there are only two bidders, there are three possibilities. If a particular bidder has submitted the highest bid-price, then she receives the amount of T-Bills requested. Otherwise, she receives the smallest of the residual demand or her bid. It is assumed that in the case of ties in the price-bid, the bills are awarded proportionally to the bid-quantities.

By exploring these features of the Treasury bill auctions, it becomes clear why the analogy of the uniform-price auction to the second-price single-unit auction is flawed. In a second-price single-unit auction, an individual's bid does not affect her profits conditional on winning since she pays the second-highest value if she wins; it only affects her probability of winning. Thus, bidding her true private value is a dominant strategy. In a uniform-price auction, however, her bid can affect her prices. Her bid for a second unit can affect how much she pays for a first unit. Therefore, in equilibrium, bidders may shade their bid-price in a uniform-price auction whereas they bid their true valuations in a second-price auction of a single object. 
The realisation that such analogy between single-unit and multiple-unit auctions is false has led to a renewal of interest in the area. Among others, Back and Zender (1993) compare the revenue generated by a uniform-price auction and by a discriminatory price auction when values are common - that is, when each bidder draws an independent signal from a fixed distribution regarding the true value of the objects - and demands are flat. Engelbrecht-Wiggans and Kahn (1998) examine uniform-price auctions where each bidder desires up to two identical, indivisible objects. They find that a bidder generally has an incentive to bid sincerely on her first object but to shade her bid on the second object.

Katzman (1995) and Tenorio (1997, 1999) provide examples where the discriminatory-price auction may generate more revenue than the uniform-price auction. In Katzman bidders desire up to two objects and in Tenorio there are two bidders, three objects and bidders have to demand two or three units so that excess demand is assumed in equilibrium.

Ausubel and Cramton (1996) consider the case where agents have constant marginal values for the good (that is, flat demands). They show that bidders have an incentive for bid shading and demand reduction in both uniform-price and discriminatory-price auction. In the uniform-price auction, the 'basic idea is that when a bidder desires multiple units of the good being auctioned, there is a positive probability that her bid on a second or later unit will be pivotal, thus determining the prices that the bidder pays on other units that she wins. Given this, she has an incentive to bid less than her true value on later units in order to reduce the price she will pay on the earlier units.' When goods are divisible, this intuition suggests a bidder submits a demand schedule similar to a monopolist's marginal-revenue curve: the vertical intercepts of the two curves coincide, but at all positive quantities the bid curve lies strictly below the true valuation curve. This phenomenon generates inefficiency in multi-unit auctions: large bidders reduce demand for additional units and so sometimes lose to smaller bidders with lower values

The example that follows, drawn from Ausubel and Cramton, shows how the demand reduction phenomenon causes inefficiencies in both discriminatory and uniform-price auctions. Suppose there are three identical objects and four buyers and that all buyers except Buyer 4 only want one object. Buyer 4 wants two objects and she values the identical objects the same. Suppose the objects are sold through a uniform-price auction where winners pay the fourth lowest bid. It is convenient to think of buyers 1,2 and 3 making a bid for one object and Buyer 4 making two bids, one for each of the two objects she wants.

Buyers 1, 2 and 3 find that their bids cannot be pivotal in any state of the world where they win a unit - that is, their bids do not influence the price they pay but only the probability of winning one unit. Therefore, they bid their true valuations. Suppose that buyers' values are distributed such that Buyer 4 has a unique optimal bid for each possible realisation of her private information, then there is a unique equilibrium in which Buyer 4 bids her true value on the first unit but shades her bid'for the second unit. By doing so she reduces the price she pays on the first unit! This equilibrium is inefficient because she may not win the 
second object even though there was another buyer with a lower valuation who won it.

Thus, in the uniform-price auction a bidder may bid below her true valuations, as it has been pointed out above. A similar example can be constructed to show that the discriminatory-price auction is also inefficient. Wolfram (1998) provides evidence for this phenomenon in bids to supply electricity in the UK, showing that bidders (sellers) offering more than one unit have an incentive to increase their bids at high quantities. In the context of procurement auctions, this phenomenon is manifested by a supply increase rather than a demand reduction as in the context of Treasury bill auctions.

Finally, Heller and Lengwiler (1998) argue that the Swiss government should continue using the uniform auction in selling government bonds. Their conclusion, however, is based on the assumption that buyers are uncertain about the amount being sold and believe that their actions cannot affect the government's decision of how much to sell.

In summary, there is no theoretical case for the choice of a uniform-price auction over a discriminatory-price auction for the sale of Treasury securities. In the next section we review some of the empirical and experimental literature that compares the two auction formats in terms of revenue and possibility of market manipulation or collusion.

\section{A Review of the Empirical and Experimental Literature}

As mentioned above, the recent US Treasury experiments with uniform-price auctions in the sale of two and five-notes have been apparently inconclusive (Malvey, Archibald and Flynn, 1996). Simon (1994) examined a similar experiment by the US Treasury when a small number of uniform-price auctions were conducted. He finds that the uniform-price lowered Treasury revenues by 3 to 4 per cent of the face value of the auctioned bonds vis-a-vis the revenue generated by discriminatory-price auctions.

Tenorio (1993) examined the revenue generated by uniform-price and discriminatory price auctions in the Zambian foreign exchange market. Zambia used first uniform-price auctions and then discriminatory-price auctions on a weekly basis from late 1985 to early 1987. Tenorio shows that the uniform-price auction generated, on average, more revenue than the discriminatory-price auction. The difference is explained by a higher participation rate under the uniform-price auction. Additional results suggest that representative agents who consistently bid high showed delayed adjustment to the regime change. Therefore, it is not clear that one should expect similar results in Treasury bill auctions with experienced bidders.

Furthermore, some laboratory experiments have tended to favor slightly the uniform-price auction as proposed by Friedman, except when bidders' demands are sufficiently steep (see, for example, Smith 1967, 1982). However, more recent experimental studies examining the role of communication among bidders prior to the auction obtain opposite results. 
In particular, Goswami, Noe and Rebello (1996) provide experimental evidence that the existence of preplay communication between bidders facilitates the adoption of collusive strategies in uniform-price auctions. In contrast,preplay communication induces the competitive equilibrium in the discriminatory-price auction. This evidence suggests that uniform-price auctions may result in lower revenues than the currently used discriminatory auction.

In conclusion, the existing empirical and experimental evidence is not sufficient to make a strong case for the use of a uniform-price auction over a discriminatory-price auction for the sale of Treasury securities.

\section{The Ascending-Price Auction}

The alternative ascending-price uniform-price mechanism proposed by the Joint Report would operate as follows. The auction would open with Treasury announcing a low price (high yield). Bidders would then submit bids simultaneously (by a computer) for the amounts they wish to purchase at the announced price. If the sum of the demands is less than the total being sold, then each bidder would receive the amount they requested at the announced price. If demand is larger than supply, then the auctioneer keeps increasing the price (reducing the yield) until the total quantity bid falls below the amount being sold. All bids at this last price would receive awards at the previous lower price (higher yield).

Menezes (1996) analyses strategic behaviour in a simultaneous ascending auction under complete information - that is, when bidders know each other's true demand functions - where bids are restricted to being nonincreasing. (As in the auction format proposed by Ausubel (1997)). The bidders' game playing means there are many equilibria. Applying a natural way of selecting one of the equilibria, Menezes shows, remarkably, that the sale takes place at the opening price. Bidders forecast how much they will eventually purchase and shrink the amounts they demand in the first round to this level, resulting in immediate sale. Although this result rests on the assumption of complete information, it provides a warning about the peculiar possibilities in simultaneous auctions. Durham, LaMaster, Smith and Van Boening (1994) find experimental evidence that such manipulation may occur. However, consistent manipulation was not observed, as it required stable coalitions, which bidders were typically unable to sustain.

Ausubel (1997) proposed an ascending-price auction mechanism that differs from the one examined above in its pricing rule. Whereas every winner pays the same price in the auction described above, the proposed auction is such that objects are awarded to bidders at the current price at which bidders are 'guaranteed' to receive a particular object given the opponents' bidding behaviour. The idea is to generalise Vickrey's insight - that a bidder should pay a price equivalent to the value of the bidder that she displaced - to ascending-price auctions (see Vickrey, 1961). Ausubel shows that this auction has an efficient equilibrium where the bidders with the highest valuations win the objects. 
Perhaps an example could be instructive. Assume full information about individuals' demands. Suppose there are three objects being sold to two bidders who value the objects as follows. Bidder 1 's values are given by $(1,1,0.1)$ and Bidder 2's values by $(0.3,0.3,0.2)$. First consider the type of equilibrium pointed out by Ausubel. Suppose the seller starts the bidding at his reservation value, say zero. Player 1 is the first to reduce his demand from three to two units at price $p=$ 0.1 . Thus Bidder 2 is guaranteed to win one of the objects at $p=0.1$. At $p=0.2$, Bidder 2 reduces his demand from three to two but Bidder 1 has not guaranteed an object yet. Finally, at price $p=0.3$ Bidder 2 reduces his demand from two to zero and Player 1 receives the two remaining objects at this price. The seller's revenue is equal to 0.7 and this equilibrium is efficient.

Note, however, that this equilibrium is not unique. Consider the equilibrium where Player 1 bids two units as long as the price is less than 1 and Player 2 bids one unit as long as the price is below 0.3 . It is easy to verify that this is an efficient equilibrium where the seller's revenue is equal to zero - the seller's opening price. Clearly, additional research is needed fully to characterise the equilibria of this auction and their properties.

\section{Conclusions}

Improved auction design could be extremely valuable both in terms of the government's revenue and market efficiency. A small decrease in the average yield obtained in the sale of Treasury notes and bonds could represent a decrease in the cost of financing the government's debt on the order of several million dollars. Perhaps this is a particularly appropriate time for policy makers to be innovative in they way they sell government securities and to experiment with new auction formats as the size of the stock of debt is declining.

Although the debate on how to sell government securities has not yet been resolved, we know that there is no basis, either from a theoretical or from an experimental/empirical perspective, for the replacement of the discriminatory price auction with a uniform-price auction. However, the government may favour instead the use an ascending-price auction along the lines suggested above.

\section{References}

Ausubel, L. (1997), 'An Efficient Ascending-Bid Auction for Multiple-Objects', University of Maryland (Working Paper 97-06).

Ausubel, L and P. Cramton (1996), 'Demand Reduction and Inefficiency in Multi-Unit Auctions', University of Maryland (Working Paper 96-07).

Back, K. and J. Zender (1993), 'Auctions of Divisible Goods: On the Rationale for the Treasury Experiment', Review of Financial Studies 6:733-764.

Bartolini, L. and C. Cottarelli (1994), 'Treasury Bill Auctions: Issues and Uses', IMF (Working Paper 94-135). 
Bikhchandani, S. and C. Huang (1993), 'The' Economics of Treasury Security Markets' Journal of Economic Perspectives 7(3):117-134.

Chari, V. and R. Weber (1992), 'How the U.S. Treasury Should Auction Its Debt', Quarterly Review 16(4):3-12, Federal Reserve Bank of Minneapolis.

Durham, V., S. La Master, V. Smith and M. Van Boening (1994), 'An Experimental Analysis of the New Treasury Auction Rules', mimeo, University of Mississippi.

Engelbrecht-Wiggans, R. and C. Kahn (1995), 'Multi-Unit Auctions with Uniform Prices', mimeo, Economic Theory 12(2):227-258.

Friedman, M. (1960), A Program for Monetary Stability, Fordham University Press, New York.

Goswami, G., T. Noe and M. Rebello (1996), 'Collusion in Uniform-Price Auctions: Experimental Evidence and Implications for Treasury Auctions', Review of Financial Studies 9(3):757-785.

Heller, D. and Y. Lengwiler (1998), 'The Auctions of Swiss Bonds: Should the Treasury Price Discriminate or Not?', US Federal Reserve Board (Working Paper 1998-11).

Katzman, B. (1995), Auctions With Diminishing Marginal Valuations, PhD Dissertation, Duke University.

Malvey, P., C. Archibald and S. Flynn (1996), 'Uniform-Price Auctions: Evaluation of the Treasury Experience’, US Treasury (Working Paper).

Menezes, F. (1999), 'Auctions of Identical Objects with Single-Unit Demands: A Survey', Australian National University (Working Papers in Economics and Econometrics no. 363), also, forthcoming in the Brazilian Review of Econometrics.

Menezes, F. M. (1996), 'Multiple-Unit English Auctions,' European Journal of Political Economy 12:671-684.

Menezes, F. and P. Monteiro (1995), 'Existence of Equilibrium in a Discriminatory Price Auction', Mathematical Social Sciences 30:285-292.

Simon, D. (1994), 'The Treasury's Experiment with Single-Price Auctions in the Mid1970s: Winner's or Taxpayer's Curse?', Review of Economics and Statistics 76:754-760.

Smith, V. (1967), 'Experimental Studies of Discrimination versus Competition in SealedBid Auction Markets', Journal of Business 40:58-84.

Smith, V. (1982), 'Microeconomic Systems as an Experimental Science,' American Economic Review 72:923-955.

Tenorio, R. (1993), 'Revenue Equivalence and Bidding Behavior in a Multi-Unit Auction Market: An Empirical Analysis', Review of Economics and Statistics 75(2):302-314. 
Tenorio, R. (1999), 'Multiple Unit Auctions with Strategic Price-Quantity Decisions', Economic Theory 13(1):247-260.

Tenorio, R. (1997), 'On Strategic Quantity Bidding in Multiple Unit Auctions,' Journal of Industrial Economics 45(2):207-217.

Vickrey, W. (1961), 'Counterspeculation, Auctions, and Competitive Sealed Tenders,' Journal of Finance 16:8-37.

Wolfram, C. (1998), 'Strategic Bidding in a Multiunit Auction: An Empirical Analysis of Bids to Supply Electricity in England and Wales', Rand Journal of Economics 29(4):703725.

This research was partly funded by $A R C$ grant F99018. The author is grateful to the Robert Albon, Steve Dowrick, Stephen King and Graeme Wells for many helpful comments. 